\title{
Respostas de licenciandos em Física sobre aspectos relacionados aos exames de diagnóstico médico por imagem ${ }^{+*}$
}

\author{
André Coelho Silva ${ }^{1}$ \\ Instituto Federal de São Paulo \\ Itapetininga $-\mathrm{SP}$ \\ Maria José P. M. Almeida ${ }^{1}$ \\ Universidade Estadual de Campinas \\ Campinas - SP
}

\section{Resumo}

Assumindo que uma das possíveis maneiras de trabalhar tópicos de Física Moderna e Contemporânea é abordando aspectos do funcionamento de artefatos tecnológicos contemporâneos, estruturamos este trabalho a partir de duas questões: como licenciandos em física produzem sentidos a partir de uma unidade de ensino sobre aparelhos e exames de diagnóstico médico por imagem? E como o desenvolvimento de uma unidade de ensino sobre aparelhos e exames de diagnóstico médico por imagem pode contribuir para as representações de licenciandos em física sobre alguns conceitos e noções associados à Física Moderna e Contemporânea? Para respondê-las, embasamo-nos em noções da Análise de Discurso divulgadas elou produzidas por Eni Orlandi e analisamos respostas dadas por dois licenciandos em física ao longo do desenvolvimento da referida unidade de ensino em sala de aula. As análises evidenciaram que a abordagem do tema aparelhos e exames de diagnóstico médico por imagem pode funcionar como condição de produção de sentidos sobre noções relacionadas à Física Moderna e Contemporânea, como as de radiação, radioatividade e spin, proporcionando aos licenciandos a produção de sentidos coerentes com as interpretações científicas atualmente aceitas.

\footnotetext{
${ }^{+}$Future Physics Teacher Answers on Aspects Related To Medical Diagnostic Imaging Exams

* Recebido: dezembro de 2018.

Aceito: setembro de 2019.

${ }^{1}$ E-mails: andco_8@yahoo.com.br; mjpmalmeida@gmail.com
} 
Palavras-chave: Exames de Imagem; Formação Inicial de Professores; Radiação; Radioatividade; Spin.

\begin{abstract}
Assuming that one of the possible ways of teaching topics of Modern and Contemporary Physics is to address aspects of the operation of contemporary technological artifacts, we structure this work from two questions: how future physics teachers produce meanings from a teaching unit on medical imaging exams? And how can the development of a teaching unit on medical imaging exams contribute to the future physics teachers' representations about some concepts and notions associated with Modern and Contemporary Physics? To answer them, we take as support notions of Discourse Analysis divulged and/or produced by Eni Orlandi and analyze answers given by two future physics teacher throughout the development of the aforementioned teaching unit in classroom. The analysis showed that the teaching of the topic medical imaging exams can work as condition for the production of meanings on notions related to Modern and Contemporary Physics, such as radiation, radioactivity and spin, providing to the future teachers the production of meanings coherent with the currently accepted scientific interpretations.
\end{abstract}

Keywords: Imaging Exams; Initial Teacher Training; Radiation; Radioactivity; Spin.

\title{
I. Introdução
}

Neste estudo analisamos respostas de dois licenciandos em física para questões formuladas durante o desenvolvimento de uma unidade de ensino em que foram trabalhados elementos da Física Moderna e Contemporânea (FMC). A temática da unidade foram artefatos tecnológicos destinados à realização de diagnósticos médicos por imagem.

Aspectos do funcionamento de boa parte dos artefatos tecnológicos contemporâneos estão baseados em conceitos de FMC, cuja inserção no Ensino Médio (EM) e a respectiva necessidade de abordagem sistemática na formação inicial de professores já foram justificadas por trabalhos como os de Terrazan (1992), Cuppari et al. (1997), Valadares e Moreira (1998), Ostermann e Cavalcanti (1999), Pinto e Zanetic (1999), Machado e Nardi (2007), Guerra, Braga e Reis (2007), Pena (2007), Silva e Almeida (2011), entre muitos outros. Entre as justificativas mais recorrentes, é possível destacar a que enfatiza a forte relação existente entre os desenvolvimentos contemporâneos da física e da tecnologia. 
Ainda que no escopo de estudos da tecnologia contemporânea e de trabalhos da linha de pesquisa Ciência, Tecnologia e Sociedade haja consenso sobre a ideia de que a tecnologia não é uma simples aplicação da ciência, não parece ser possível desprezar as influências mútuas entre ambas (GARDNER, 1999; CUPANI, 2006).

Também não é difícil notar que, em muitos casos, o acesso aos artefatos tecnológicos contemporâneos tem aumentado nos últimos anos - embora possamos problematizar questões políticas e econômicas relacionadas ao acesso de grande parte da população a alguns desses artefatos.

No que se refere ao acesso aos exames de diagnóstico médico por imagem, dados do Ministério da Saúde (DATASUS, 2018) sobre a quantidade de equipamentos desse tipo no Brasil indicam como ele tem aumentado ao longo dos anos. Em novembro de 2008, havia 83.637 equipamentos de diagnóstico médico por imagem disponíveis no país, incluindo equipamentos do Sistema Único de Saúde (SUS) e equipamentos de clínicas/hospitais privados. Em novembro de 2013 esse número saltou para 114.978 (crescimento de 37\%), chegando a 140.351 em novembro de 2018 - um aumento de 68\% em dez anos. De novembro de 2008 a novembro de 2018, o número de aparelhos de radiografia cresceu 52\%, de aparelhos de mamografia $63 \%$, de aparelhos de tomografia computadorizada $98 \%$ e de aparelhos de ressonância magnética $215 \%$. No que se refere à quantidade de aparelhos de PET-CT (aparelhos de tomografia por emissão de pósitrons acoplados a aparelhos de tomografia computadorizada), em novembro de 2018 estavam disponíveis no Brasil 73, 38 deles no SUS. Trata-se de um tipo de equipamento introduzido no país apenas em agosto de 2014, chegando ao SUS em novembro desse mesmo ano (DATASUS, 2018).

Tendo em vista esses apontamentos, consideramos que uma das possíveis maneiras de trabalhar tópicos de FMC no EM e na formação de professores de física é abordando aspectos do funcionamento de artefatos tecnológicos contemporâneos. Como boa parte dos aparelhos de diagnóstico médico por imagem tem relação com as radiações, tópico que costuma ser bastante valorizado no escopo da FMC, decidimos investigar como se dão os processos de produção de sentidos durante o desenvolvimento de uma unidade de ensino sobre essa temática. Embasados em noções da Análise de Discurso (AD) divulgadas e/ou desenvolvidas por Eni Orlandi, analisamos informações de cunho empírico com o intuito de buscar respostas para as seguintes questões:

I) Como licenciandos em física produzem sentidos a partir de uma unidade de ensino sobre aparelhos e exames de diagnóstico médico por imagem?

II) Como o desenvolvimento de uma unidade de ensino sobre aparelhos e exames de diagnóstico médico por imagem pode contribuir para as representações de licenciandos em física sobre alguns conceitos e noções associados à FMC?

A seguir, apresentamos as noções da $\mathrm{AD}$ que se constituíram como nosso suporte teórico-metodológico, descrevemos de que forma se deu o trabalho pedagógico com a unidade de ensino sobre os aparelhos e exames de diagnóstico médico por imagem e como foram 
coletadas as informações empíricas. Por fim, analisamos respostas dadas por dois licenciandos ao longo de seus percursos durante a unidade com o intuito de respondermos às questões propostas.

\section{Suporte teórico-metodológico: algumas noções da AD}

O homem não pode, assim, evitar a interpretação, ou ser indiferente a ela. Mesmo que ele nem perceba que está interpretando - e como está interpretando - é esse um trabalho contínuo na sua relação com o simbólico (ORLANDI, 2007, p. 10).

Justificamos a escolha da $\mathrm{AD}$, na vertente que teve em Michel Pêchux, na França, nos anos 1960, seu principal organizador, por concordarmos com as noções divulgadas/estabelecidas por Orlandi e por se tratar de obras que temos estudado e utilizado enquanto fundamentação teórico-metodológica para a condução de pesquisas no escopo da área de Ensino de Física/Ciências. Nosso intuito de compreender de que forma se deram os processos de produção de sentidos guarda coerência com os propósitos da $\mathrm{AD}$, pois, para ela, a interpretação em si não é a finalidade:

[...] A interpretação é o sentido pensando-se o co-texto (as outras frases do texto) e o contexto imediato. Em uma situação " $x$ " Maria diz que Antonio vai ao cinema. João pergunta como ela sabe e ela responde: "Ele disse isso". Interpretando: "ele" é Antonio e "o que" ele disse é que vai ao cinema. No entanto, a compreensão é muito mais do que isso. Compreender é saber como um objeto simbólico (enunciado, texto, pintura, música etc.) produz sentidos. É saber como as interpretações funcionam. Quando se interpreta já se está preso em um sentido. A compreensão procura a explicitação dos processos de significação presentes no texto e permite que se possam "escutar" outros sentidos que ali estão, compreendendo como eles se constituem. Por exemplo, nas palavras de Maria, pode-se compreender que ela não quer ir, ou que Antonio é quem decide tudo, ou que ele está indo em outro lugar etc. [...] Em suma, a Análise de Discurso visa a compreensão de como um objeto simbólico produz sentidos, como ele está investido de significância para e por sujeitos. [...] (ORLANDI, 2005, p. 26).

Além de recusar a transparência da linguagem, ou seja, a ideia de que as palavras e os sentidos estabelecem entre si uma relação de univocidade, a AD admite que a possibilidade de o sentido vir a ser outro não é um defeito de comunicação, mas sim um efeito intrínseco relacionado ao fato de que os sentidos derivam da inscrição da língua na história. Os discursos, enquanto objetos teóricos que representam os efeitos de sentidos produzidos entre os interlocutores, são compostos de maneira constitutiva pelas condições imediatas e sóciohistóricas em que são produzidos, as chamadas condições de produção do discurso (ORLANDI, 1997, 2005). 
Como são as relações entre as condições de produção e a linguagem que atuam junto à produção de sentidos, tais condições oferecem a possibilidade de múltiplas interpretações, mas também limitam a abrangência desse espectro: o sentido pode ser outro, mas não pode ser qualquer um. Na dependência das condições de produção, os dizeres serão inscritos em umas ou em outras regiões do espaço discursivo, retomando uns ou outros sentidos. Esse espaço discursivo constituído por todos os discursos já produzidos é denominado na AD de memória discursiva ou interdiscurso. Ele é composto por regiões, as chamadas formações discursivas (ORLANDI, 2005). A palavra peso, por exemplo, pode retomar diferentes sentidos préexistentes, dependendo das inscrições que ocorrerem no interdiscurso. Se ela se inscrever em uma formação discursiva associada à física, passa a designar uma força, a força peso (grosso modo, a atração exercida pelo planeta Terra junto aos corpos). Já se essa inscrição ocorrer em formações discursivas associadas ao mercado financeiro/cambial ou até mesmo ao senso comum, o sentido será totalmente diferente.

A AD considera que a relação do sujeito com a realidade é mediada de maneira constitutiva pelo imaginário. Logo, por meio dele produzimos imagens no campo discursivo, isto é, representações de aspetos dessa realidade (ORLANDI, 1987, 2005). Temos, por exemplo, representações sobre o que caracteriza um bom professor, sobre o que caracteriza um bom aluno, sobre como se comportar numa entrevista de emprego, sobre o que se deve ensinar na física do EM, sobre o que significa radiação, sobre como funciona um artefato tecnológico contemporâneo como um aparelho de ressonância magnética etc.

Em síntese, podemos afirmar que a AD propõe situar os gestos de interpretação dos sujeitos, situar o que foi dito, investigar de onde o sujeito está falando, de onde ele está retomando sentidos, em que formações discursivas seus dizeres estão sendo inscritos, que aspectos das condições de produção parecem ter relevância para as formulações feitas, que aspectos de sua "história de vida" são retomados em sua fala etc. Além dos princípios básicos da $\mathrm{AD}$, na análise das respostas dos estudantes nos referimos basicamente à noção de representação.

\section{Condições de produção do trabalho empírico}

Fundamentados em noções da AD e no estudo do tema a partir de fontes especializadas $^{2}$, produzimos uma unidade de ensino que teve como objetivo geral proporcionar a compreensão de aspectos do funcionamento dos aparelhos e exames de radiografia, tomografia computadorizada (CT), tomografia por emissão de pósitrons (PET) e ressonância magnética $(\mathrm{RMN})$. Considerando que ela foi planejada para ser trabalhada pedagogicamente com licen-

\footnotetext{
2 Bilaniuk e Bilaniuk (1984); Bonagamba, Capelle e Azevedo (2005); Chazan (2003); CNEN (2014); Corneliussen (2014); Ferreira (2013); Johansson, Nilsson e Tegner (2006); Keevil (2001); Lima, Afonso e Pimentel (2009); Martins (1990); Martins (1997); Martins (1998); Martins (2003); Martins (2004); Michael (2001); Navarro et al. (2008); Okuno (1988); Okuno (2013); Okuno e Yoshimura (2010); Ortega (2006); Osei e Darko (2013); Redberg e Smith-Bindman (2014); Robilotta (2006); Schmidt (1973); Sienkiewicz (2003) e Van Gelderen (2004).
} 
ciandos em física, seus objetivos específicos foram: I) Proporcionar aos licenciandos interpretações coerentes com a física acerca de aspectos do funcionamento da radiografia, da CT, da PET e da RMN, especialmente no que tange às radiações; II) Fomentar o desenvolvimento por parte dos licenciandos de posturas críticas sobre questões políticas, sociais, culturais e econômicas associadas à ciência e à tecnologia; III) Proporcionar o desenvolvimento das habilidades de leitura e escrita dos licenciandos; IV) Fomentar a autonomia dos licenciandos no que se refere à busca de informações que possam complementar/problematizar as interpretações produzidas durante as aulas; V) Impulsionar o desenvolvimento de representações que apontem para a relevância em trabalhar no EM tópicos relacionados à radiografia, à $\mathrm{CT}$, à PET e à RMN.

Para atingirmos os objetivos específicos III e IV, organizamos momentos durante as aulas em que os licenciandos realizaram atividades de leitura e escrita. Além disso, organizados em grupos, os licenciandos desenvolveram um trabalho em que entrevistaram profissionais da área da saúde e pacientes que já haviam realizado os referidos exames de imagem (trabalho que foi apresentado na $15^{\mathrm{a}}$ aula da disciplina). A decisão sobre as perguntas que seriam feitas ficou sob responsabilidade dos próprios licenciandos, ou seja: eles tiveram autonomia para formular os roteiros de entrevistas.

Para atingirmos o objetivo específico II, durante as aulas da unidade de ensino discutimos, entre outros aspectos: a relação entre a situação socioeconômica da população e o acesso aos exames de imagem mais modernos; a recorrente omissão de informação por parte de clínicas e profissionais da saúde no que se refere aos riscos associados à realização de determinados exames; o aumento de solicitações para a realização de exames de imagem que, em certos casos, poderiam ser substituídos por métodos clínicos de diagnóstico.

Já o alcance do objetivo específico $\mathrm{V}$ foi assumido como consequência das experiências vivenciadas pelos licenciandos ao longo da unidade de ensino. Em outras palavras: assumimos que o desenvolvimento de representações que apontem para a relevância em trabalhar no EM tópicos relacionados aos exames de imagem seria consequência da atribuição de relevância à temática pelos licenciandos em relação às suas próprias formações e em relação à formação geral das pessoas no âmbito do Ensino Básico.

$\mathrm{A}$ avaliação de se, como e em que medida os objetivos específicos II e V foram ou não alcançados foi foco de análise em outros artigos. Nesse sentido, conforme anunciado na primeira seção, o foco deste artigo é analisar de que forma o objetivo específico I foi atingido. Essa afirmação não significa, contudo, assumir uma visão de mundo fragmentada, como se as respostas dos licenciandos relativas à produção de sentidos sobre conceitos físicos e o funcionamento dos exames de imagem não fossem perpassadas e estivessem amparadas em elementos de cunho político, social, cultural e econômico. Vale lembrar que, de acordo com a AD, não são apenas as condições de produção imediatas que intervêm junto à produção de sentidos. Ou seja: os sentidos produzidos não dependem apenas do contexto das aulas da unidade de ensino, do que foi falado e do que não foi falado nessas aulas, mas também das condições 
de produção sócio-históricas, dos discursos em circulação na época em que as informações foram coletadas, das histórias de vida dos participantes etc.

É necessário explicitar que a unidade de ensino foi trabalhada numa disciplina obrigatória de um curso de Licenciatura em Física de uma instituição pública federal cujo professor efetivo era o primeiro autor deste artigo. Tratava-se de uma disciplina da área de Ensino de Física que tinha como objetivo pensar questões associadas ao ensino de FMC. Não havia pré-requisito para cursá-la, mas a grade curricular do curso a recomendava para o oitavo semestre, o último do curso.

A unidade de ensino ocupou parte ou integralmente onze das dezenove aulas da disciplina (aulas 1, 3, 4, 5, 6, 7, 8, 10, 15, 18 e 19), sendo que cada aula tinha duração de 150 minutos. Durante as aulas utilizamos diferentes recursos e estratégias de ensino: leitura de textos por nós elaborados, apresentação de vídeos ${ }^{3}$, apresentação de simuladores didáticos computacionais $^{4}$, aulas expositivas dialógicas etc. Ao final deste artigo, apresentamos como anexo trechos dos textos lidos pelos licenciandos no âmbito da unidade de ensino. Entre os tópicos associados à FMC abordados durante essas aulas estiveram: raios X (o que são, como foram descobertos, como são produzidos, como são utilizados na radiografia e na CT); radiação e radiação ionizante (o que são, diferentes tipos, radiação corpuscular e eletromagnética); ondas eletromagnéticas (o que são, como são produzidas, espectro); radioatividade (o que é, como foi descoberta, tipos de emissões radioativas e decaimentos, séries radioativas, conceito de meia-vida, radioatividade induzida); contaminação e irradiação (o que as difere e em que casos cada uma delas pode ocorrer); e spin (o que é, como o conceito foi proposto, como os spins se comportam quando se aplica um campo magnético externo, como eles podem ser afetados por ondas eletromagnéticas e como se relacionam a um exame de ressonância magnética). A fim de fomentar o desenvolvimento de certa consciência sobre o uso responsável e criterioso das radiações na área de saúde, foram contemplados também durante a unidade de ensino aspectos biológicos e de proteção radiológica (riscos associados à exposição à radiação ionizante, efeitos teciduais e estocásticos, princípios de proteção à radiação ionizante). $\mathrm{Na}$ seção seguinte, por meio da transcrição de falas do professor e da apresentação de trechos de textos lidos pelos licenciandos durante as aulas, daremos mais detalhes sobre como os tópicos mencionados neste parágrafo foram abordados.

Dado o caráter da disciplina em que a unidade de ensino foi trabalhada - uma disciplina da área de Ensino de Física - e o fato de que seu público-alvo eram licenciandos em física, isto é, a princípio, futuros professores de física do EM, o tratamento conceitual dispensado aos assuntos não envolveu aprofundamentos que, ao nosso ver, não fariam sentido nesse contexto. A expectativa foi possibilitar aos licenciandos a produção de sentidos sobre conhe-

\footnotetext{
3 Vídeos como <https://www.youtube.com/watch?v=tYmMtSWPQEI> e <https://www.youtube.com/watch?v=TRL7o2kPqw0>. Acesso em: 26 dez. 2018.

${ }^{4}$ Simuladores como <https://phet.colorado.edu/pt_BR/simulation/alpha-decay> e $<$ https://phet.colorado.edu/pt_BR/simulation/mri>. Acesso em: 26 dez. 2018.
} 
cimentos básicos associados aos exames de imagem, para que, com base nesses conhecimentos, eles pudessem refletir sobre a relevância e a pertinência de trabalhar o tema com um público mais amplo, especialmente no contexto escolar do nível médio. Consideramos que a abordagem de especificidades relativas à Radiologia poderiam fazer mais sentido em cursos como o de Física Médica e não num curso de Licenciatura em Física. Nesse sentido, não foram feitas discussões que envolvessem questões como: a utilização das transformadas de Fourier para a construção das imagens de ressonância magnética a partir dos sinais detectados pelo aparelho; a pertinência de minimizar a ocorrência do efeito Compton a fim de potencializar o reconhecimento das bordas dos tecidos/órgãos em exames como radiografia e CT; as configurações e ajustes disponíveis em cada tipo de aparelho etc. Também não foi abordado o formalismo matemático associado aos exames de imagem e à física envolvida.

Diferentes instrumentos de coleta de informações foram utilizados na pesquisa, entre eles: a gravação em áudio das aulas da unidade de ensino e a aplicação de questionários escritos: questionário inicial (QI) - aula 1; questionário sobre os exames (QE) - aula 3; questionário final (QF) - aula 18; questionário de avaliação da disciplina (QAD) - aula 19; e questionários ao final de cada aula que compôs a unidade de ensino (Q3, Q4, Q5, Q6, Q7, Q8, Q10, Q15 - o número representa a aula da disciplina em que o questionário foi aplicado). A entrega de todos os questionários respondidos valia $25 \%$ da média final na disciplina.

\section{Análise das informações coletadas}

Dos oito licenciandos que cursaram a disciplina, sete aceitaram colaborar com a pesquisa mediante a assinatura de um Termo de Consentimento Livre e Esclarecido - a pesquisa foi aprovada pelo Comitê de Ética em Pesquisa da instituição. Nenhum deles era formando, seja porque estavam antecipando a disciplina ou porque estavam defasados em relação à expectativa de concluir o curso em quatro anos. Há que se mencionar também que os licenciandos ainda não tinham tido muito contato formal com tópicos de FMC durante o curso. De fato, nenhum deles havia cursado disciplinas como Física Moderna, Física Atômica e Molecular e Relatividade.

Com o objetivo de respondermos às questões propostas neste artigo, apresentamos, a seguir, análises de respostas dadas por dois licenciandos durante o desenvolvimento da unidade de ensino: Frederico e Joelma (nomes fictícios). Trata-se dos casos mais emblemáticos dentre os sete licenciandos, pois evidenciam, por um lado, a manutenção de determinadas representações sobre alguns conceitos e noções associados à FMC e, por outro, a alteração delas. Os outros cinco licenciandos oscilaram entre esses extremos.

Nas duas próximas subseções, apresentamos indícios da produção de sentidos e de possíveis alterações nas representações desses dois estudantes. Há que se pontuar que mantivemos as ortografias originais utilizadas nas respostas. 


\section{IV.1. Algumas respostas de Frederico}

Quanto ao funcionamento da radiografia, já no QE, aplicado no início da terceira aula da disciplina, antes do início da abordagem dos exames de diagnóstico médico por imagem, Frederico deu indícios de que sua representação sobre o assunto possuía desvios em relação aos conhecimentos considerados científicos ao responder que a radiografia tem relação com a radioatividade. $\mathrm{Na}$ resposta à pergunta: "O desenvolvimento da tecnologia tem ajudado bastante o desenvolvimento da física e, por outro lado, o desenvolvimento de conhecimentos na física tem contribuído para inúmeros desenvolvimentos tecnológicos, desde aqueles que serviram para a guerra até aos que ajudaram muita gente a viver mais. Como você acha que a física contribuiu para o desenvolvimento: a) Do aparelho de radiografia (raio-X)?”, o licenciando escreveu (grifos nossos):

Descoberta da radioatividade e que através dela é possivel obter imagens de órgãos e ossos e como se proteger dela, assim, foi descoberto outros compostos químicos radioativos.

Esse equívoco parece ser fruto da confusão entre os significados de radioatividade e de radiação ionizante, ou mesmo estar associado à representação de que radioatividade e raios $\mathrm{X}$ são a mesma coisa. Possivelmente ele ouviu falar sobre ambos em diferentes situações e buscou associá-los em sua resposta.

No Q3, aplicado ao final da terceira aula da disciplina, ao ser solicitado: "Escreva uma carta a um amigo(a) explicando-lhe sobre a aula de hoje", Frederico escreveu (grifo nosso):

A aula [...] foi muito interessante, pois foi estudado, utilizando vídeos e conversa com a turma, sobre exames médicos que estão relacionados à radioatividade [...].

Nessa aula, após a aplicação do QE, feita no início da aula, introduzimos por meio de um vídeo alguns dos exames com os quais trabalharíamos nas aulas seguintes. Embora todos tenham relação com a radiação, o único que tem relação com a radioatividade é a PET.

Nos questionários aplicados ao final da quarta (Q4) e da sexta aulas (Q6) - que tiveram como temas, respectivamente, raios $\mathrm{X}$ e ondas eletromagnéticas, e radiografia e $\mathrm{CT}$, ao responder às questões: "Escreva uma carta a um amigo(a) explicando-lhe sobre a aula de hoje"; e "Escreva o que você explicaria a um(a) amigo(a) sobre a aula de hoje", Frederico novamente indica que suas representações sobre esses assuntos associavam a radiografia com a radioatividade (grifos nossos):

\footnotetext{
5 <https://www.youtube.com/watch?v=i9ipk4t_E-Y>. Acesso em: 19 set. 2019.
} 
Primeiramente, foi discutido sobre um texto muito interessante sobre a descoberta de Wilhelm Rotgen, os raios $X$, e como foi a reação da sociedade quanto a isso. Além de que, antigamente não se usavam proteção contra a radioatividade, os problemas que surgiam nas pessoas que tiravam uma radiografia não era a causa da radioatividade [...].

Depois, foi feito uma discussão sobre raio x e tomografia computadorizada, e foi concluído que o raio $X$ além de ser mais barato, tem menos riscos em questão de liberação de radioatividade [...].

Em suas respostas, o licenciando retomou trechos dos textos lidos durante a quarta e a sexta aulas. Fez, contudo, alterações equivocadas nesses trechos, tentando escrevê-los com as "suas palavras" acabou substituindo "raios X" e "radiação ionizante" por "radioatividade" - o que novamente sugere a presença da representação de que radioatividade e raios X são sinônimos. A seguir, os trechos dos textos que provavelmente embasaram essas respostas de Frederico:

Em dezembro de 1895 Röntgen publicou o primeiro artigo sobre o assunto, enviando, no início de janeiro de 1896, cópias do artigo acompanhadas de radiografias (chamadas naquela época de "fotografias de Röntgen") para físicos reconhecidos da época. Logo depois, a descoberta foi divulgada em jornais de diversos tipos e ele se tornou famoso. [...] Radiografar partes do corpo e até mesmo pequenos animais se tornou diversão ao redor do mundo e outras aplicações não demoraram a surgir [...] Apesar desse entusiasmo, muitas pessoas se sentiram desconfortáveis e ameaçadas pela ideia de que suas imagens poderiam se tornar públicas [...] Em 1896, um professor da Universidade de Vanderbilt (EUA) convenceu seu chefe a tirar uma radiografia da cabeça. A queda de seus cabelos nas semanas seguintes acabou virando piada. Em outros casos foram observados vermelhidão, dormência, queda de pelos, infecção, dores agudas e descamação. A culpa por esses efeitos adversos foi colocada inicialmente no gás ozônio que era gerado pelas máquinas, no calor e na umidade excessivos nas salas em que os exames eram realizados, na alta corrente elétrica necessária ao funcionamento dos aparelhos ou até mesmo numa suposta alergia. A possibilidade de que os problemas fossem causados pelos próprios raios $X$ não foi admitida de imediato.

Embora uma imagem de CT tenha maior qualidade que uma imagem radiográfica convencional, esta ainda é a técnica mais utilizada. Possíveis explicações são o baixo custo, a simplicidade, a pequena quantidade de radiação ionizante recebida, a rapidez do exame [...] A CT costuma ser indicada nos casos em que a radiografia convencional não consegue ser muito efetiva. Nesse sentido, embora a dose de radiação ionizante recebida seja consideravelmente maior [...]

Já no QF, aplicado na $18^{\mathrm{a}}$ aula da disciplina, embora em alguns momentos Frederico tenha continuado a manifestar esse equívoco, em outros parece passar a distinguir radiação e radioatividade. Nas respostas apresentadas a seguir, os grifos são nossos e as anotações entre 
colchetes no início de cada trecho sintetizam o que foi solicitado por cada uma das perguntas que o licenciando respondeu:

[Que tópicos de FMC trabalharia com seus alunos no ensino médio e de que maneira faria isso]: [...] os principais nomes e as maiores destruições radioativas, além de exemplos sobre o que contém radiação.

[Sobre a radiografia]: Exame de imagem que emite radioatividade (é possível visualizar fraturas ou outras doenças).

[Sobre a CT]: Exame de imagem que emite maior taxa de radiação.

[Sugestões de como abordar os raios X e a radioatividade no ensino médio]: Mostre também alguns exames de imagem que utilizam radiação no seu funcionamento, além de elementos da natureza que sejam radioativos porém com baixíssimas taxas de radioatividade.

[Sobre os riscos envolvidos com os exames de imagem]: [...] Se você não faz exames frequentemente, apenas quando realmente é necessário, a radiação não causará efeito nenhum no seu corpo.

O primeiro trecho sugere que Frederico acredita que há elementos/materiais que contêm radiação, algo como se a radiação fosse uma substância. Já no quarto trecho, o licenciando apontou a existência de elementos radioativos na natureza - o que é adequado segundo o conhecimento científico a respeito do assunto.

No segundo trecho, assim como ocorreu no âmbito dos questionários QE, Q3, Q4 e Q6, conforme respostas que apresentamos anteriormente, o licenciando novamente deu indícios de que sua representação sobre a radiografia a relacionava com a radioatividade. Por outro lado, no terceiro, no quarto e no quinto trechos, Frederico utilizou corretamente o termo radiação, ainda que o ideal fosse tê-lo adjetivado com a palavra ionizante no terceiro e no quinto trechos.

Há que se mencionar que no quinto trecho, Frederico dá a entender que existe uma quantidade segura de radiação ionizante que se pode receber, isto é, uma quantidade abaixo da qual não haveria nenhum dano biológico. Embora ainda seja um assunto controverso, a posição dominante é a de que qualquer dose de radiação ionizante, por menor que seja, tem a probabilidade de causar danos ao ser humano que a recebe (OKUNO; YOSHIMURA, 2010; FERREIRA, 2013) - a controvérsia e a posição dominante foram discutidas durante a unidade de ensino.

Em conjunto, esses apontamentos podem ser tomados como indícios de que, mesmo ao final do trabalho pedagógico com a unidade de ensino, as representações de Frederico sobre raios $\mathrm{X}$, radioatividade, radiação e radiação ionizante se mostraram confusas e diferentes das aceitas pela física. Conforme evidenciado pelas respostas que apresentamos, o licenciando 
parece ter retomado sentidos de formações discursivas associadas à física apenas em alguns momentos do QF.

No QE, ao ser questionado sobre de que forma a física contribuiu para o desenvolvimento do aparelho de ressonância magnética, Frederico respondeu:

\section{Algo relacionado ao magnetismo?}

Ao indicar incerteza por meio de uma frase interrogativa, o licenciando oferece um indício para afirmarmos que sua representação sobre o assunto ainda não estava bem formulada, carecendo de especificidade. De fato, a presença do adjetivo "magnética" no nome do exame, ao sugerir que se trata de algo que envolve magnetismo, parece ter funcionado como condição de produção para a resposta de Frederico.

No Q8, aplicado ao final da oitava aula da disciplina, aula que teve como tema spin e ressonância magnética, à questão: "Escreva uma carta a um amigo(a) explicando-lhe sobre a aula de hoje", Frederico respondeu:

A aula de hoje teve o foco no spin e ressonância magnética. O spin é definido como propriedade de partícula, relacionado ao magnetismo, porém essa definição não é mais aceita pela física pois existem vários motivos que contradiz essa afirmação (que a partícula gira em torno dela mesma): - Se a partícula é um ponto material, sem dimensão, como ele pode girar ao redor de si mesmo? Entre outros motivos citados em sala, sendo importante ressaltar que até hoje não se tem uma explicação para a origem do spin. [...]

Sua resposta remete a trechos da aula, sendo composta por partes idênticas e partes modificadas das falas do professor, conforme transcrição apresentada a seguir a partir dos áudios gravados:

Professor: “[...] propuseram que o elétron tem uma rotação ao redor dele mesmo, um spin [...] e, consequentemente, um magnetismo intrínseco [...] Eles propuseram que a origem do spin era a rotação do elétron ao redor dele mesmo [...] Então toda partícula tem um spin associado [...] Só que essa interpretação do spin, ou seja, de magnetismo intrínseco da partícula como resultado do giro da partícula ao redor dela mesma, tem alguns problemas com essa interpretação. [...] Por exemplo, o elétron, qual é o tamanho de um elétron? [...] Pelo nosso conhecimento atual da física, o elétron é um ponto material, o elétron não tem dimensão [...] Como que um ponto vai girar ao redor de si mesmo? [...] Segundo [...] Será que essa interpretação do spin como o giro da partícula ao redor dela mesma é uma boa interpretação? E a conclusão de hoje em dia é que não é uma boa interpretação. [...] Mas então o que eles falam que é o spin? [...] 
Eles falam que o spin é uma propriedade intrínseca das partículas. [...] Então não há uma explicação para a origem do spin. [...]".

Já no QF, ao responder à questão: Escreva o que você contaria a um(a) amigo(a) a respeito da ressonância magnética, Frederico escreveu (grifos nossos):

Existe um campo magnético que liberam ondas e alinha os spins.

Ainda que continue carecendo de especificidade, em comparação à resposta dada no QE, é possível notar que o licenciando passou a utilizar conceitos físicos centrais na explicação do funcionamento da ressonância magnética, como campo magnético, ondas e spin. Há que se ressaltar também que ao escrever "alinha os spins", Frederico evidencia que sua representação sobre o spin passou a incorporar os sentidos de que é possível associar a ele orientação espacial e de que campos magnéticos podem afetar essa orientação, ambos retomados de formações discursivas relacionadas ao conhecimento da física. De fato, podemos afirmar que o acesso dos licenciandos a essas formações discursivas foi possibilitado na oitava aula a partir de um texto e da mediação do professor. O texto lido durante a aula continha o seguinte trecho:

A RMN funciona basicamente da seguinte maneira: primeiro, é necessário aplicar um campo magnético homogêneo, constante e intenso à amostra. Isso, para fazer com que alguns spins nucleares se alinhem aproximadamente a favor do campo magnético e outros aproximadamente contrários a ele, sendo que cada uma dessas configurações possui uma energia característica - nomearemos de $Y$ a diferença entre essas energias [...] Se for aplicado agora um pulso eletromagnético composto por fótons cuja energia corresponda exatamente à diferença de energia $Y$, alguns dos núcleos em situação de menor energia absorverão a energia desses fótons e passarão a ocupar o estado mais energético de alinhamento spin/campo magnético. Vale ressaltar que na produção de imagens médicas o pulso eletromagnético aplicado sempre está na faixa de ondas de rádio. [...]

Tendo como base suas respostas ao QF e os sentidos que compõem formações discursivas associadas à física - tomados como os sentidos desejáveis no contexto em tela -, enviamos individualmente para Frederico (assim como para todos os licenciandos que cursaram a disciplina) um email indicando aspectos adequados e equivocados que se fizeram presentes em suas respostas. Como a disciplina já havia se encerrado, essa foi a forma de tentarmos esclarecer os equívocos que foram apresentados pelos licenciandos ao final da unidade de ensino, buscando direcionar suas produções de sentido àqueles que consideramos os desejáveis. 


\section{IV.2 Algumas respostas de Joelma}

No QE, aplicado antes das discussões relativas aos exames de imagem, ao responder à pergunta: "O desenvolvimento da tecnologia tem ajudado bastante o desenvolvimento da física e, por outro lado, o desenvolvimento de conhecimentos na física tem contribuído para inúmeros desenvolvimentos tecnológicos, desde aqueles que serviram para a guerra até aos que ajudaram muita gente a viver mais. Como você acha que a física contribuiu para o desenvolvimento: a) Do aparelho de radiografia (raio-X)? b) Do aparelho de tomografia computadorizada? c) Do aparelho de ressonância magnética? d) Do aparelho de tomografia por emissão de pósitrons?", Joelma escreveu (grifos nossos):

a) Com o descobrimento das ondas de Raio-X e depois aprimoramento das máquinas. b) Não sei. c) Com o desenvolvimento da compreensão do eletromagnetismo $e$ suas aplicações. d) Não tenho conhecimento ainda.

Palavras que costumeiramente relacionamos à física, como ondas, raios $\mathrm{X}$ e eletromagnetismo, fizeram-se presentes na resposta de Joelma. Por outro lado, elas aparecem nas respostas aos itens "a" e "c" de maneira bastante superficial, sem maiores esclarecimentos. De fato, informações como as de que os raios X são um tipo de onda eletromagnética e de que os fenômenos elétricos e magnéticos estão inter-relacionados, originando a área da física conhecida como eletromagnetismo parecem estar frequentemente em circulação no âmbito de um curso de física.

Já no QF, aplicado na $18^{\mathrm{a}}$ aula da disciplina, ao ser questionada: Escreva o que você contaria a um(a) amigo(a) a respeito: a) Da radiografia. b) Da tomografia computadorizada. c) Da tomografia por emissão de pósitrons (PET). d) Da ressonância magnética, a licencianda respondeu da seguinte maneira (grifos nossos):

a) É um exame com procedimento simples, mas que não deixa de envolver riscos, pois é feito com radiação ionizante.

b) É um exame muito similar ao exame de raio $X$, os princípios físicos são os mesmos, é emitida uma radiação no paciente onde é captada por sensores em um computador e é feita uma imagem, essa parte de ser captada por um computador que é diferente do exame de raio $X$, pois é um equipamento que fica girando em torno do paciente para poder ser feita a imagem, que por conta disso a imagem é feita em $3 D$. Também usa radiação ionizante.

c) Apesar de levar o mesmo nome do último exame, seu procedimento é diferente, ao invés da pessoa receber radiação, ela emite a radiação para ser detectada, ela emite pósitrons, por isso o nome do exame, isso acontece porque a pessoa ingere um radiofármaco, que por decaimento, emitirá pósitrons que se aniquilaram com elétrons emitindo fótons de raios gama, esses serão detectados, a tomografia é feita junto 
para que seja feita uma imagem 3D. É também perigoso, pois usa radiação ionizante.

d) Um exame que não são conhecidos efeitos que são prejudiciais a saúde, usa o spin dos elétrons para fazer os exames.

É bastante relevante que Joelma tenha sido capaz de destacar os principais aspectos do funcionamento dos quatro exames abordados durante a unidade de ensino, utilizando na redação de suas respostas diversas noções que podem ser associadas à física: radiação ionizante; radiação; receber radiação; emitir radiação; pósitrons; radiofármacos; decaimento; aniquilação; elétrons; fótons; raios gama e spin. As únicas ressalvas a serem feitas são em relação às respostas aos itens "c" e "d". Nestas a licencianda afirma que a ressonância magnética funciona com base no spin dos elétrons, quando, na verdade, ela funciona com base no spin dos núcleos atômicos - o que, no caso dos exames de imagem, se resume ao spin do próton que compõe o núcleo dos átomos de hidrogênio. Já na resposta ao item "c", Joelma afirma que a CT é combinada com a PET para gerar uma imagem em três dimensões. Entretanto, o acoplamento da CT à PET tem como objetivo primordial possibilitar a associação de aspectos anatômicos aos aspectos fisiológicos proporcionados pela realização de uma PET. De fato, como tanto a PET quanto a CT são tomografias, ambas, isoladamente, já possibilitam a obtenção de imagens tridimensionais. Joelma também dá a entender que numa PET o paciente apenas emite radiação. Entretanto, parte dessa radiação emitida é depositada no próprio paciente - ele recebe a radiação que está emitindo. Não fica claro se a licencianda está ciente disso, embora a admissão dos perigos do exame - explícita na mesma resposta - ofereça indícios nessa direção.

Em especial, destacamos a maneira fisicamente rigorosa pela qual a licencianda usou os conceitos de radiação e radiação ionizante, não recorrendo em nenhum momento à palavra radioatividade, como se ela fosse algo como um sinônimo de raios $\mathrm{X}$ ou radiação ionizante. Nesse sentido, temos indícios de que o trabalho pedagógico com a unidade de ensino parece ter se constituído como condição de produção para que Joelma tivesse acesso a interpretações cientificamente aceitas a respeito do funcionamento da radiografia, da CT, da PET e da RMN.

Joelma abordou o funcionamento dos exames com bastante propriedade, o que funciona como indício para afirmarmos que a licencianda se colocou efetivamente como autora de seus dizeres - sendo a autoria, para a AD:

[...] uma função da noção de sujeito, responsável pela organização do sentido e pela unidade do texto [...] a função-autor se realiza toda vez que o produtor da linguagem se representa na origem, produzindo um texto com unidade, coerência, progressão, não-contradição e fim. [...] o autor consegue formular, no interior do formulável, e se constituir, com seu enunciado, numa história de formulações. $O$ que significa que, embora ele se constitua pela repetição, esta é parte da história e não mero exercício mnemônico. Ou seja, o autor, embora não instaure discursividade (como o autor "original" de Foucault), produz, no entanto, um lugar de inter- 
pretação no meio dos outros. Esta é sua particularidade. [...] Porque assume sua posição de autor (se representa nesse lugar), ele produz assim um evento interpretativo. O que só repete (exercício mnemônico) não o faz (ORLANDI, 2007, p. 69).

Outro indício que pode corroborar a afirmação de que Joelma se colocou como autora de seus dizeres é o fato de que o QF foi aplicado cerca de dois meses após o término das discussões sobre o funcionamento dos aparelhos e exames de diagnóstico médico por imagem - o QF foi aplicado na aula 18 e o término das discussões sobre os exames se deu na aula 10. Nesse intervalo foram tratados outros assuntos de FMC que compunham a disciplina e/ou apresentados trabalhos pelos licenciandos.

\section{Considerações finais}

As análises realizadas evidenciam que o desenvolvimento de uma unidade de ensino sobre aparelhos e exames de diagnóstico médico por imagem pode atuar junto às representações de licenciandos em física sobre alguns conceitos e noções associados à FMC ao possibilitar-lhes o contato com sentidos oriundos de formações discursivas relacionadas ao conhecimento físico. Em outras palavras: como a interpretação científica de aspectos do funcionamento dos aparelhos e exames de imagem está imbricada com a interpretação científica dos conceitos físicos envolvidos, a abordagem desse tema se constitui como condição de produção de sentidos sobre noções relacionadas à FMC.

Por outro lado, as diferenças entre as respostas de Frederico e Joelma reforçam que embora possamos considerar que o trabalho pedagógico com a unidade de ensino atuou como a principal condição de produção de sentidos pelos licenciandos, sempre há também outras condições em jogo, entre elas: a memória dos sujeitos e todo o conjunto de representações que trazem consigo cristalizadas; a possibilidade de terem tido ao longo de suas histórias de vida mais ou menos contato com sentidos oriundos de formações discursivas que não estão associadas ao conhecimento científico - consolidando em maior ou menor grau representações incoerentes com esses conhecimentos; e a possibilidade de terem tido outros contatos com sentidos oriundos de formações discursivas associadas à física, seja durante aulas de outras disciplinas ou por meio da leitura de textos sobre o assunto, do acesso a reportagens veiculadas na televisão etc.

De fato, nossas análises apontaram que nas aulas finais da unidade de ensino, enquanto Frederico alternava entre a retomada de sentidos provenientes de formações discursivas não associadas ao conhecimento científico (mantendo sua posição inicial) e a retomada de sentidos provenientes de formações discursivas associadas à física (alterando sua posição inicial); Joelma foi capaz de efetivamente incorporar às suas representações sentidos provenientes de formações discursivas associadas à física. A partir dessa observação, finalizamos este artigo reforçando a importância de que, em situações de ensino, levemos em consideração as diferentes interpretações dos estudantes. Ou seja, ao estruturarmos as condições de produção 
imediatas das aulas, é pertinente considerar a existência das condições de produção sóciohistóricas, bem como o fato de que elas não são idênticas para todos os estudantes. Além disso, a compreensão das diferentes possibilidades de interpretação dos estudantes contribui significativamente para a estruturação de outras possíveis aulas semelhantes.

\section{Agradecimentos}

Ao Conselho Nacional de Desenvolvimento Científico e Tecnológico (CNPq).

\section{Referências}

BILANIUK, L. T.; BILANIUK, O. M. NMR imaging in medicine. Physics Education, v. 19, n. 5 , p. $247-252,1984$.

BONAGAMBA, T. J.; CAPELLE, K. W.; AZEVEDO, E. R. A RMN e suas aplicações atuais. Ciência Hoje, v. 37, n. 221, p. 40-48, 2005.

CHAZAN, L. K. O Corpo Transparente e o Panóptico Expandido: Considerações sobre as Tecnologias de Imagem nas Reconfigurações da Pessoa Contemporânea. PHYSIS: Revista de Saúde Coletiva, v. 13, n. 1, p. 193-214, 2003.

CNEN - COMISSÃO NACIONAL DE ENERGIA NUCLEAR. Diretrizes Básicas de Proteção Radiológica, março 2014. Disponível em: <http://appasp.cnen.gov.br/seguranca/ normas/pdf/Nrm301.pdf>. Acesso em: 21 nov. 2014.

CORNELIUSSEN, S. T. Are we "silently irradiating ourselves to death" in medical imaging? Physics Today, fevereiro 2014.

CUPANI, A. La peculiaridade del conocimiento tecnológico. Scientiae Studia, v. 4, n. 3, p. 353-371, 2006.

CUPPARI, A. et al. Gradual introduction of some aspects of quantum mechanics in a high school curriculum. Physics Education, v. 32, n. 5, p. 302-308, 1997.

DATASUS, Ministério da Saúde. Informações de Saúde (TABNET) - Rede Assistencial, Cadastro Nacional dos Estabelecimentos de Saúde do Brasil, Recursos Físicos, Equipamentos. 2018. Disponível em: <http://www2.datasus.gov.br/DATASUS/index.php?area= 0204\&id=11671\&VObj=http://tabnet.datasus.gov.br/cgi/deftohtm.exe?cnes/cnv/equipo>. Acesso em: 26 dez. 2018. 
FERREIRA, Mário. O efeito das radiações ionizantes em doses baixas - cinco décadas de disputa. Com Ciência: revista eletrônica de jornalismo científico, outubro 2013.

GARDNER, P. L. The representation of science-technology relationships in Canadian physics textbooks. International Journal of Science Education, v. 21, n. 3, p. 329-347, 1999.

GUERRA, A.; BRAGA, M.; REIS, J. C. Teoria da relatividade restrita e geral no programa de mecânica do ensino médio: uma possível abordagem. Revista Brasileira de Ensino de Física, v. 29, n. 4, p. 575-583, 2007.

JOHANSSON, K. E.; NILSSON, C.; TEGNER, P. E. An educational PET camera model. Physics Education, v. 41, n. 5, p. 437-439, 2006.

KEEVIL, Stephen F. Magnetic resonance imaging in medicine. Physics Education, v. 36, n. 6, p. 476-485, 2001.

LIMA, R. S.; AFONSO, J. C.; PIMENTEL, L. C. F. Raios-X: fascinação, medo e ciência. Química Nova, v. 32, n. 1, 2009.

MACHADO, D. I.; NARDI, R. Construção e validação de um sistema hipermídia para o ensino de física moderna. Revista Electrónica de Enseñanza de las Ciencias, v. 6, n. 1, p. 90$116,2007$.

MARTINS, R. A. Como Becquerel não descobriu a radioatividade. Caderno Brasileiro de Ensino de Física, v. 7, n. especial, p. 27-45, 1990.

MARTINS, R. A. Investigando o invisível: as pesquisas sobre raios X logo após a sua descoberta por Röntgen. Revista da Sociedade Brasileira de História da Ciência, v. 17, p. 81102, 1997.

MARTINS, R. A. A descoberta dos raios X: o primeiro comunicado de Röntgen. Revista Brasileira de Ensino de Física, v. 20, n. 4, p. 373-391, 1998.

MARTINS, R. A. As primeiras investigações de Marie Curie sobre elementos radioativos. Revista da Sociedade Brasileira de História da Ciência, v. 1, n. 1, p. 29-41, 2003.

MARTINS, R. A. Hipóteses e interpretação experimental: a conjetura de Poincaré e a descoberta da hiperfosforescência por Becquerel e Thompson. Ciência \& Educação, v. 10, n. 3, p. 501-516, 2004. 
MICHAEL, G. X-ray computed tomography. Physics Education, v. 36, n. 6, p. 442-451, 2001.

NAVARRO, M. V. T.; LEITE, H. J. D.; ALEXANDRINO, J. C.; COSTA, E. A. Controle de riscos à saúde em radiodiagnóstico: uma perspectiva histórica. História, Ciências, Saúde Manguinhos, v. 15, n. 4, p.1039-1047, 2008.

OKUNO, E. Radiação: efeitos, riscos e benefícios. São Paulo: Harbra, 1988.

OKUNO, E. Efeitos biológicos das radiações ionizantes. Acidente radiológico de Goiânia. Estudos Avançados, v. 27, n. 77, p. 185-199, 2013.

OKUnO, E.; YOSHIMURA, E. M. Física das radiações. São Paulo: Oficina de Textos, 2010.

ORLANDI, E. P. A linguagem e seu funcionamento: as formas do discurso. São Paulo: Pontes, 1987.

ORLANDI, E. P. Análise de discurso: princípios \& procedimentos. $6^{\text {a }}$ ed. Campinas: Pontes, 2005.

ORLANDI, E. P. Interpretação: autoria, leitura e efeitos do trabalho simbólico. 5. ed. Campinas: Pontes, 2007.

ORLANDI, E. P. Leitura e discurso científico. Cadernos Cedes, n. 41, 1997.

ORTEGA, F. O corpo transparente: visualização médica e cultura popular no século XX. História, Ciências, Saúde - Manguinhos, v. 13 (suplemento), p. 89-107, 2006.

OSEI, E. K; DARKO, J. A Survey of Organ Equivalent and Effective Doses from Diagnostic Radiology Procedures. ISRN Radiology, v. 2013, 2013. Disponível em: <http://www.hindawi.com/journals/isrn/2013/204346/abs/>. Acesso em: 21 nov. 2014.

OSTERMANN, F.; CAVALCANTI, C. J. H. Física moderna e contemporânea no ensino médio: elaboração de material didático, em forma de pôster, sobre partículas elementares e interações fundamentais. Caderno Catarinense de Ensino de Física, v. 16, n. 3, p. 267-286, 1999. 
PENA, F. L. A. Por que, nós professores de Física do Ensino Médio, devemos inserir tópicos e ideias de física moderna e contemporânea na sala de aula? Revista Brasileira de Ensino de Física, v. 28, n. 1, p. 1-2, 2006.

PINTO, A. C.; ZANETIC, J. É possível levar a Física Quântica para o ensino médio? Caderno Catarinense de Ensino de Física, v. 16, n. 1, p. 7-34, 1999.

REDBERG, R. F.; SMITH-BINDMAN, R. We are giving ourselves cancer. The New York Times, Opinion Pages, 30 de janeiro de 2014.

ROBILOTTA, C. C. A tomografia por emissão de pósitrons: uma nova modalidade na medicina nuclear brasileira. Revista Panamericana de Salud Pública, v. 20, n. 2/3, p. 134-142, 2006.

SCHMIDT, R. H. X-ray physics for radiologic technologists. St. Louis: W. H. Green, 1973.

SIENKIEWICZ, Z. International Workshop on Non-Ionizing Radiation Protection in Medicine. Medical Physics, v. 40, n. 11, p. 1-7, 2013.

SILVA, A. C.; ALMEIDA, M. J. P. M. Física Quântica no Ensino Médio: o que dizem as pesquisas. Caderno Brasileiro de Ensino de Física, v. 28, n. 3, p. 624-652, 2011.

TERRAZAN, E. A. A inserção da física moderna e contemporânea no ensino de Física na escola de $2^{\circ}$ grau. Caderno Brasileiro de Ensino de Física, v. 9, n. 3, 1992.

VALADARES, E. C.; MOREIRA, A. M. Ensinando Física moderna no segundo grau: Efeito fotoelétrico, laser e emissão de corpo negro. Caderno Catarinense de Ensino de Física, v. 15, n. 2, p. 121-135, 1998.

VAN GELDEREN, F. Understanding X-rays: a synopsis of radiology. Berlin: Springer, 2004.

\section{Anexos}

I) Trechos do texto utilizado na quarta aula da disciplina: aspectos históricos e culturais relacionados à descoberta dos Raios $\mathrm{X}$

Este texto procura abordar de maneira sintética como se deu a descoberta dos raios $\mathrm{X}$ e como ela repercutiu na sociedade da época. Nesse sentido, talvez seja relevante pontuar que no final do século XIX, não havia aviões, não havia automóveis, os telefones eram raros e a 
eletricidade era precária. A principal forma de comunicação era o correio e o combustível utilizado para a iluminação das ruas era o gás (SEGRÈ, 1987).

Nessa época Wilhelm Röntgen, estava trabalhando com tubos de raios catódicos (elétrons acelerados) quando notou algo diferente. Sabia-se que os raios catódicos não atravessavam o vidro nem outros corpos, exceto folhas metálicas finas. Mesmo o ar os absorve, extinguindo-os após atravessarem alguns centímetros. Röntgen notou, entretanto, que alguma coisa produzida no tubo de raios catódicos estava atravessando papeis, madeira, placas metálicas e até mesmo grandes distâncias no ar. Era algo invisível e capaz de sensibilizar chapas fotográficas. Buscando caracterizar as propriedades do que havia observado, Röntgen trabalhou intensamente e em sigilo durante semanas. Por serem de natureza desconhecida, nomeou-os de raios X (MARTINS, 1997; 1998).

\section{[...]}

Apesar desse entusiasmo, muitas pessoas se sentiram desconfortáveis e ameaçadas pela ideia de que suas imagens poderiam se tornar públicas, especialmente imagens de seus órgãos genitais. Relatos da época indicam que indústrias têxteis teriam até mesmo anunciado a produção de calcinhas à prova de raios X. Era uma época em que a privacidade, a intimidade, a repressão sexual e a vergonha do corpo nu eram elementos socialmente preponderantes. Até mesmo trajes para ir à praia ou à piscina costumavam cobrir os corpos da cabeça aos pés. Havia fronteiras marcantes entre o público e o privado, tanto é que em nota publicada no jornal Pall Mall Gazette de Londres quatro meses após a descoberta dos raios X, evidenciam-se as preocupações com as possibilidades de que se possam ver os ossos das outras pessoas até mesmo a olho nu e de que se possa ver o que ocorre através dos muros e portas das casas. $\mathrm{O}$ autor dessa nota sugeriu que se estabelecesse uma legislação severa para restringir o uso dos raios $X$. Sugeriu ainda que os trabalhos sobre raios $X$ fossem queimados e que os pesquisadores fossem executados (ORTEGA, 2006; CHAZAN, 2003).

Mesmo com esses focos de desconfiança, logo após a descoberta já era possível obter radiografias das mãos pagando relativamente pouco. Muitas pessoas construíram suas próprias máquinas caseiras. Estúdios especializados em tirar esses "retratos" foram abertos. Poemas, quadrinhos e histórias foram escritos. Detetives faziam propaganda dizendo que com os raios $\mathrm{X}$ poderiam seguir cônjuges infiéis. As imagens de raios $\mathrm{X}$ haviam agregado valor sentimental (ORTEGA, 2006).

$[\ldots]$

Em 1896, um professor da Universidade de Vanderbilt (EUA) convenceu seu chefe a tirar uma radiografia da cabeça. A queda de seus cabelos nas semanas seguintes acabou virando piada. Em outros casos foram observados vermelhidão, dormência, queda de pelos, infecção, dores agudas e descamação. A culpa por esses efeitos adversos foi colocada inicialmente no gás ozônio que era gerado pelas máquinas, no calor e na umidade excessivos nas salas em que os exames eram realizados, na alta corrente elétrica necessária ao funcionamento dos apa- 
relhos ou até mesmo numa suposta alergia. A possibilidade de que os problemas fossem causados pelos próprios raios X não foi admitida de imediato (VAN GELDEREN, 2004).

\section{Referências}

CHAZAN, L. K. O Corpo Transparente e o Panóptico Expandido: Considerações sobre as Tecnologias de Imagem nas Reconfigurações da Pessoa Contemporânea. PHYSIS: Revista de Saúde Coletiva, v. 13, n. 1, p. 193-214, 2003.

MARTINS, R. A. A descoberta dos raios X: o primeiro comunicado de Röntgen. Revista Brasileira de Ensino de Física, v. 20, n. 4, p. 373-391, 1998.

MARTINS, R. A. Investigando o invisível: as pesquisas sobre raios X logo após a sua descoberta por Röntgen. Revista da Sociedade Brasileira de História da Ciência, n. 17, p. 81102, 1997.

ORTEGA, F.: O corpo transparente: visualização médica e cultura popular no século XX. História, Ciências, Saúde - Manguinhos, v. 13 (suplemento), p. 89-107, 2006.

SEGRÈ, E. Dos Raios X aos Quarks: físicos modernos e suas descobertas. Brasília: Editora Universidade de Brasília, 1980.

VAN GELDEREN, F. Understanding X-rays: a synopsis of radiology. Berlin: Springer, 2004.

II) Trechos do texto utilizado na sexta aula da disciplina: Alguns aspectos do funcionamento dos aparelhos de radiografia e de tomografia computadorizada

[...] Este texto procura abordar de maneira mais específica como os raios X são utilizados para produzir imagens médicas, tanto no que diz respeito aos aparelhos de radiografia quanto no que diz respeito aos aparelhos de tomografia computadorizada (CT: computed tomography).

Ao notar que os raios $\mathrm{X}$ eram capazes de percorrer distâncias relativamente longas até se extinguirem, o próprio Röntgen supôs que eles poderiam atravessar materiais de baixa densidade - como os músculos; e serem absorvidos por materiais com densidades mais elevadas - como os ossos. Para verificar sua hipótese, convenceu sua esposa a participar de um de seus experimentos (MARTINS, 1997).

De fato, tanto as radiografias (os chamados “exames de raios X") quanto as CT's são realizadas considerando a diferença entre a "quantidade" de raios X que atinge o corpo e a que é capaz de atravessá-lo. Os ossos, por exemplo, absorvem eficazmente os raios X, dife- 
rentemente dos músculos - da mesma forma que uma parede de concreto é capaz de absorver luz visível, diferentemente de uma parede de vidro, que é atravessada por ela. Substâncias constituídas por elementos de alto número atômico, como cálcio (20), bário (56) e iodo (53), absorvem mais os raios $\mathrm{X}$ quando comparado com aquelas constituídas por elementos de baixo número atômico, como hidrogênio (1), carbono (6) e oxigênio (8) (OKUNO; YOSHIMURA, 2010).

\section{[...]}

Por se tratar de algo como uma sombra, uma projeção bidimensional de determinada parte do corpo, a radiografia convencional não funciona bem para diagnosticar certos problemas - uma estrutura pode estar na frente da outra, por exemplo. Nesses casos, uma das possibilidades é recorrer a uma CT, técnica desenvolvida por Godfrey Hounsfield e Allan Cormack em 1967 (MICHAEL, 2001).

Embora também sejam produzidas a partir de raios $\mathrm{X}($ tomo $=$ camadas; grafia $=$ figura), as imagens de CT são tridimensionais, pois o equipamento é capaz de girar ao redor da área examinada de maneira a obter dados referentes à absorção da radiação em diferentes ângulos. Esses sinais são enviados a um computador, o qual, após processá-los, transforma-os em imagem. O computador permite realçar, colorir, aumentar ou diminuir a imagem, o que confere certa liberdade no processamento dos dados (ORTEGA, 2006).

\section{$[\ldots]$}

Embora uma imagem de CT tenha maior qualidade que uma imagem radiográfica convencional, esta ainda é a técnica mais utilizada. Possíveis explicações são o baixo custo, a simplicidade, a pequena quantidade de radiação ionizante recebida, a rapidez do exame (menos de um minuto, em geral) e a adequação a procedimentos rotineiros como o diagnóstico de fraturas, a mamografia e a densitometria óssea. A CT costuma ser indicada nos casos em que a radiografia convencional não consegue ser muito efetiva. Nesse sentido, embora a dose de radiação ionizante recebida seja consideravelmente maior e o exame seja um pouco mais demorado (menos de cinco minutos, em geral), trata-se de um procedimento capaz de fornecer mais detalhes, possibilitando diagnosticar uma gama maior de problemas e de maneira mais precoce.

\section{Referências}

MARTINS, R. A. Investigando o invisível: as pesquisas sobre raios $\mathrm{X}$ logo após a sua descoberta por Röntgen. Revista da Sociedade Brasileira de História da Ciência, v. 17, p. 81$102,1997$.

MICHAEL, G. X-ray computed tomography. Physics Education, v. 36, n. 6, p. 442-451, 2001. 
OKUnO, E.; YOSHIMURA, E. M. Física das radiações. São Paulo: Oficina de Textos, 2010.

ORTEGA, F. O corpo transparente: visualização médica e cultura popular no século XX. História, Ciências, Saúde - Manguinhos, v. 13 (suplemento), p. 89-107, 2006.

\section{III) Trechos do texto utilizado na sétima aula da disciplina: $O$ Aparelho de Tomografia por Emissão de Pósitrons: alguns fundamentos}

Em aulas anteriores, vimos que a radioatividade foi descoberta em 1896 por Henri Becquerel e que Marie Curie, Pierre Curie, Ernest Rutherford, entre outros, ajudaram no entendimento desse fenômeno. Vimos também que as radiações emitidas pelos compostos radioativos são de três tipos: alfa, beta e gama. Enquanto as radiações alfa e beta são radiações corpusculares, a radiação gama é uma radiação eletromagnética. A radiação beta pode ser subdividida em beta menos (elétrons muito rápidos) e beta mais (pósitrons muito rápidos). Este texto procura abordar de que maneira a radiação emitida por compostos radioativos é utilizada pelos aparelhos de tomografia por emissão de pósitrons (PET: Positron Emission Tomography) na produção de imagens médicas.

Como o próprio nome indica, numa tomografia por emissão de pósitrons são utilizados pósitrons, o que requer a presença de elementos radioativos que sofram decaimento beta mais na região do corpo a ser examinada. Portanto, diferentemente do que ocorre na radiografia, na CT e na ressonância magnética, onde a radiação é transmitida para o corpo a partir de uma fonte externa, na PET a radiação é emitida dentro do próprio corpo por elementos radioativos.

Há que se frisar, contudo, que o aparelho não produz as imagens detectando os pósitrons emitidos. Ocorre que quando um pósitron interage com sua antipartícula, o elétron, eles se aniquilam convertendo suas massas em energia, mais especificamente, em dois fótons de raios gama. É a detecção desses fótons que permitirá ao aparelho determinar onde as aniquilações estão ocorrendo e produzir, a partir disso, as imagens resultantes do exame (ROBILOTTA, 2006).

\section{[...]}

Uma imagem feita por meio de uma PET não permite distinguir estruturas anatômicas (o fígado do rim, por exemplo), afinal, trata-se de uma imagem com "borrões" que representam as regiões em que os radiofármacos estão concentrados. Devido a isso, atualmente existem aparelhos que combinam a PET com a CT. O chamado sistema PET-CT foi desenvolvido em 2000 nos EUA por David Townsend e colaboradores. Trata-se de um acoplamento, ou seja, o mesmo aparelho é capaz de produzir uma sobreposição de dois tipos de imagens. A CT permite obter imagens estruturais, anatômicas. Já a PET permite obter imagens capazes de rastrear as funções metabólicas do organismo, possibilitando diagnósticos precoces de al- 
gumas doenças, uma vez que alterações anatômicas, em alguns casos, só se manifestam em estágios mais avançados (ROBILOTTA, 2006).

$[\ldots]$

\section{Referência}

ROBILOTTA, C. C. A tomografia por emissão de pósitrons: uma nova modalidade na medicina nuclear brasileira. Revista Panamericana de Salud Pública, v. 20, n. 2/3, p. 134-142, 2006.

\section{IV) Trechos do texto utilizado na oitava aula da disciplina: Ressonância Magnética: al- guns fundamentos}

$[\ldots]$

Como prótons e nêutrons possuem spin, um núcleo atômico terá um spin resultante, um spin nuclear, o qual pode ser diferente de zero - condição esta necessária para a aplicação da ressonância magnética, ou, de maneira mais técnica, da ressonância magnética nuclear (RMN) (KEEVIL, 2001).

[...]

A RMN funciona basicamente da seguinte maneira: primeiro, é necessário aplicar um campo magnético homogêneo, constante e intenso à amostra. Isso, para fazer com que alguns spins nucleares se alinhem aproximadamente a favor do campo magnético e outros aproximadamente contrários a ele, sendo que cada uma dessas configurações possui uma energia característica - nomearemos de $\mathrm{Y}$ a diferença entre essas energias, a qual depende do valor do campo magnético aplicado. Além disso, em temperatura ambiente, há pequena predominância de núcleos na situação de menor energia (BONAGAMBA; CAPELLE; AZEVEDO, 2005; BILANIUK; BILANIUK, 1984; KEEVIL, 2001).

Se for aplicado agora um pulso eletromagnético composto por fótons cuja energia corresponda exatamente à diferença de energia $\mathrm{Y}$, alguns dos núcleos em situação de menor energia absorverão a energia desses fótons e passarão a ocupar o estado mais energético de alinhamento spin/campo magnético. Vale ressaltar que na produção de imagens médicas o pulso eletromagnético aplicado sempre está na faixa de ondas de rádio. Trata-se, portanto, de radiação não ionizante (BONAGAMBA; CAPELLE; AZEVEDO, 2005; BILANIUK; BILANIUK, 1984; KEEVIL, 2001).

Após ganharem energia, os núcleos a devolverão em forma de radiação novamente na faixa de ondas de rádio - sinal que será detectado por bobinas (como se fossem antenas) e transformado em imagem. Esse processo de retorno ao nível de menor energia não é imediato: o tempo associado a ele (chamado de tempo de relaxação) e, por consequência, os sinais obtidos, dependem sensivelmente do ambiente químico em torno dos núcleos. Dessa forma, a diferença entre regiões mais claras e escuras em uma imagem de RMN está relacionada à di- 
ferença de tempos de relaxação de núcleos (BONAGAMBA; CAPELLE; AZEVEDO, 2005; BILANIUK; BILANIUK, 1984; KEEVIL, 2001).

$[\ldots]$

\section{Referências}

BILANIUK, L. T.; BILANIUK, O. M. NMR imaging in medicine. Physics Education, v. 19, n. 5 , p. 247-252, 1984.

BONAGAMBA, T. J.; CAPELLE, K. W.; AZEVEDO, E. R. A RMN e suas aplicações atuais. Ciência Hoje, v. 37, n. 221, p. 40-48, 2005.

KEEVIL, S. F. Magnetic resonance imaging in medicine. Physics Education, v. 36, n. 6, p. 476-485, 2001. 